\title{
An ecological and evolutionary analysis of photosynthetic thermotolerance using the temperature-dependent increase in fluorescence
}

\author{
Charles A. Knight • David D. Ackerly
}

Keywords Acclimation $\cdot$ Fluorescence $\cdot$ Photosystem II $\cdot$ Phylogenetic contrasts $\cdot$ Plasticity

\begin{abstract}
The hypothesis that species inhabiting warmer regions have greater photosynthetic tolerance of high temperatures was tested using the temperature-dependent increase in fluorescence $\left(T-F_{\mathrm{o}}\right)$. Congeneric species pairs of Atriplex, Salvia, Encelia, and Eriogonum with desert versus coastal distributions were studied in a common environment and in the field. In addition, 21 species with contrasting microclimate distributions were studied at a field site in a northern California chaparral community. The average July maximum temperature within the current distributions of species was quantified using a geographic information system. Four parameters $\left(T_{\text {crit }}, T_{\mathrm{S} 20}\right.$, $T_{50}$, and $T_{\max }$ ) of the $T-F_{\mathrm{o}}$ response were used to quantify photosynthetic thermotolerance. In the common environment, only the desert Atriplex species was significantly greater for all $T-F_{\mathrm{o}}$ parameters when compared to its coastal congener. In the field, desert species had significantly greater $T_{\text {crit }}, T_{\mathrm{S} 20}, T_{50}$, and $T_{\max }$ when compared to coastal species. The magnitude of variation between species and between genera was similar in the common environment and the field. However, $T_{\text {crit }}, T_{\mathrm{S} 20}, T_{50}$ and $T_{\max }$ were all significantly greater when measured in the field. There was no relationship between $T-F_{\mathrm{o}}$ parameters and the microclimate distribution of the 21 species at the chaparral field site. In addition, $T-F_{\mathrm{o}}$ parameters for all 35 species were not correlated with the average July maximum temperature within the species ranges. However, there was a significant negative correlation between the average annual amount of precipitation inside species' ranges and $T_{\mathrm{S} 20}$. Our results show that photosynthetic thermotolerance is (1) significantly different between genera and species, (2) highly plastic, (3) not necessarily greater for species with warm climate distributions when measured in a common environment, but (4) significantly greater overall for desert species compared to coastal species when measured in the field.
\end{abstract}

\section{Introduction}

Previous studies have shown that the temperature-dependent increase in fluorescence is correlated with a number of physiological factors including the decline in photosynthetic capacity (Schreiber and Berry 1977; Seemann et al. 1979, 1986; Downton et al. 1984) and the onset of irreversible tissue damage following high temperature stress (Bilger et al. 1984). These observations have led to the hypothesis that species with warm climate distributions should have greater intrinsic photosynthetic thermotolerance and thus the temperature-dependent increase in fluorescence should occur at higher temperatures (Smillie and Nott 1979; Bilger et al. 1984). While there has been considerable work on the photosynthetic thermotolerance of desert plants utilizing the temperature-dependent increase in fluorescence (Seemann et al. 1979, 1986; Downton et al. 1984) few comparative studies have been conducted across contrasting habitats or climates (but see Smillie and Nott 1979; Berry and Bjorkman 1980). As a result, the question still remains whether there is a correlation between photosynthetic thermotolerance and the temperature regime within a species' distribution.

The fluorescence emitted by plant leaves is produced during the rapid decay of excited electrons. Increased fluorescence at high temperatures is caused by a disruption of electron transport, which leaves a greater proportion of excited electrons to decay (Schreiber and Armond 1978; Bukhov et al. 1990; Yamane et al. 2000). Increased membrane fluidity (Raison et al. 1982), the dissociation of primary electron acceptors $\mathrm{Q}_{\mathrm{A}}$ and $\mathrm{Q}_{\mathrm{B}}$ (Bilger et al. 1984; Bukhov et al. 1990), and the separation of light harvesting complex II from the oxygen evolving complex of photosystem II (Yamane et al. 1997) are all thought to contribute to increased fluorescence at high temperatures. To compare leaves, the in- 
Table 1 List of abbreviations used

\begin{tabular}{ll}
\hline Abbreviation & Definition \\
\hline$F_{\mathrm{o}}$ & Fluorescence \\
$T-F_{\mathrm{o}}$ & Temperature-dependent rise of steady state fluorescence $\left(F_{\mathrm{o}}\right)$ \\
$T_{\text {crit }}$ & Critical temperature of $T-F_{\mathrm{o}}$, calculated by intersecting a line modeled on the slow \\
$T_{\mathrm{S} 20}$ & rise phase of the curve, with a line modeled on the fast rise phase. \\
$T_{50}$ & Temperature at which the slope of the $T-F_{\mathrm{o}}$ response reaches $20 \%$ of its maximum \\
$T_{\max }$ & Temperature at which $F_{\mathrm{o}}$ reaches $50 \%$ of its maximum \\
PDI & Temperature at which $F_{\mathrm{o}}$ reaches its maximum \\
July $_{\max }$ & Potential diurnal insolation \\
AP & Anly maximum temperature \\
\hline
\end{tabular}

A
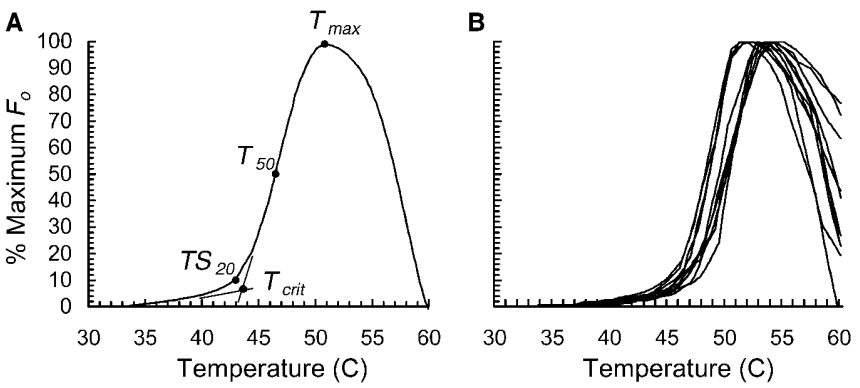

Fig. 1 A An example $T-F_{0}$ curve with $T_{\text {crit }}, T_{\mathrm{S} 20}, T_{50}$ and $T_{\max }$ indicated. Refer to Table 1 for definition of terms. $\mathbf{B}$ Ten replicate $T-F_{\mathrm{o}}$ curves for Encelia california in the common garden

flection point $\left(T_{\text {crit }}\right)$ is often calculated by finding the intersection of lines extrapolated from the slow and fast rise portion of the temperature-dependent fluorescence response $\left(T-F_{0}\right.$, Fig. $\left.1 \mathrm{~A}\right)$

Comparisons of many species from contrasting environments in several different common environments should be the basis for inferences concerning the evolution of photosynthetic thermotolerance. However, information at this scale is difficult to obtain. Most studies involve a limited set of species from either heterogeneous environments or a single common environment. Evolutionary studies concerning photosynthetic thermotolerance are further complicated by the fact that a variety of environmental factors including plant water status (Seemann et al. 1979, 1986; Havaux 1992; Valladares and Pearcy 1997), growth temperature (Schreiber and Berry 1977; Seemann et al. 1979, 1986; Downton et al. 1984), soil salinity (Larcher et al. 1990), and light levels (Schreiber and Berry 1977; Weis 1982; Havaux and Strasser 1992) can affect the plastic state of photosynthesis. In addition, photosynthetic acclimation can occur on the scale of minutes to hours in response to moderately elevated temperatures (Havaux 1993), and comparable leaves from different individuals of a single species in the same environment can also exhibit considerable variation (Fig. 1B).

The goal of this study was to test the hypothesis that species with warm-climate distributions have greater photosynthetic thermotolerance (measured by the temperature-dependent increase in fluorescence) when compared to species with cooler-climate distributions. This hypothesis was addressed at two scales. First, we compared $T-F_{\mathrm{o}}$ parameters for four congeneric species pairs where species within a pair had contrasting hot-desert and cool-coastal distributions, both in an experimental common environment and in the field. Several additional species were measured at the two field sites to make general comparisons of realized photosynthetic thermotolerance between coastal and desert communities. We expected that species from the desert would have higher $T-F_{\mathrm{o}}$ breakpoints both in the common environment and in the field. Second, we compared $T-F_{0}$ parameters for 21 species with contrasting microclimate distributions at a field site in the northern California chaparral. Again, we expected that species commonly found in warmer and more exposed microclimates would have higher temperature $T-F_{0}$ breakpoints when compared to species from cooler microclimates. We also compared results obtained using four different $T-F_{\mathrm{o}}$ parameters, two roughly equivalent to the $T-F_{\mathrm{o}}$ breakpoint, and the temperatures at which fluorescence increases to $50 \%$ and $100 \%$ of its maximum (see Table 1).

\section{Materials and methods}

Species selection

Congeneric species pairs used in this study were screened from a geographic information system (GIS) database of evergreen perennial shrubs in the California flora. The GIS database consists of information on the presence or absence of species in each of 35 different sub-regions of California as well as the elevational distribution of each species (Hickman 1993). This information was used to create coarse-scale species range maps using ArcView GIS software (ESRI, Redlands, Calif., USA). Climate maps of mean July maximum temperature ( July $_{\max }$ ) and annual precipitation (AP) were intersected with the species range maps resulting in a histogram of the percentage of each species range falling into several different temperature or precipitation classes (climate maps were obtained from the Oregon State University PRISM project; Daly et al. 1994, 1997). From this histogram mean July max $_{\text {and AP }}$ inside each species distribution were calculated as an estimate of differences between species for realized climatic niche parameters (see Austin et al. 1990; Westman 1991; Franklin 1998). We select-

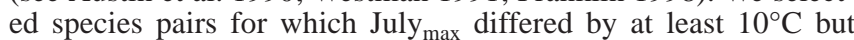
with minimal differences in precipitation. The genera selected were Atriplex, Eriogonum, Encelia, Salvia, and Isocoma (field on1y). Selection of species pairs that differ by a large amount in an independent variable has been suggested as an effective strategy for testing trait divergence (Westoby et al. 1998). Simulations have shown that this approach has both appropriate type I error 
and high statistical power for detecting correlated trait changes based on comparative data, though it may introduce bias into estimates of correlation coefficients (Ackerly 2000).

\section{Field and common garden populations}

Seeds were collected from field populations of candidate species pairs in the spring of 1998. Desert populations were near the Desert Studies Center (operated by California State University in the Mojave Desert, $35^{\circ} 11^{\prime} \mathrm{N}, 116^{\circ} 4^{\prime} \mathrm{W}$ ). Coastal populations were collected in the Santa Monica and Santa Ynez Mountains north of Santa Barbara. Physiological work for these populations was conducted at the Sedgwick Reserve (operated by the University of California, $\left.34^{\circ} 37^{\prime} \mathrm{N}, 120^{\circ} 5^{\prime} \mathrm{W}\right)$. Seeds were germinated in vermiculite and later transplanted to variable grain size sand in $20-\mathrm{cm}-$ diameter and 50-cm-deep pots in a glasshouse at the Plant Growth Facility on the campus of Stanford University. Separate pots for approximately 50 individuals of each species within a congeneric pair were established together in a rectangular block (see Table 1 for the list of species). Each genus had its own block. Within a block, pots for the two species were arranged in an alternating matrix. The mean daytime temperature in the glass house was $25^{\circ} \mathrm{C}$ during the day and $15^{\circ} \mathrm{C}$ during the night. The plants were fertilized monthly, and the amount of nutrient addition was determined so that adequate growth and healthy foliage was maintained with a minimal amount of fertilizer. Nutrient addition was identical for species within a pair. The plants were grown in this common environment for over a year before the first measurements were made. In May 2000, the parent field populations of the common garden species pairs were revisited and the physiological parameters listed below were measured with identical methodology as for the measurements made in the common garden. Most of the co-occurring dominant species at the two field sites were also measured (see Table 4 for the list of species).

Potential diurnal insolation and microclimate distribution in the Jasper Ridge Biological Preserve chaparral

The microclimate distribution for the dominant chaparral shrub species at Jasper Ridge Biological Preserve was quantified by multiple transects across north- and south-facing slopes with 311 regularly spaced vegetation plots (Ackerly et al., in press). The potential diurnal insolation (PDI) within the microclimate distribution of each species at Jasper Ridge was calculated using a GIS model involving the slope, aspect and topographic position of each $5 \times 5$-m grid cell (Ackerly et al., in press). Over the coarse of approximately 4 weeks in late May and June 1999, 10-12 leaves from each species were collected for $T-F_{0}$ determination (see Table 4 for the list of species). Replicate leaves for each species were randomly sampled throughout the course of the observations, and no more than two leaves of the same species were sampled on the same day.

\section{Leaf temperature measurements in the field}

Five shrub canopy temperatures (one for each congeneric species at each field site) were monitored from May to July 2000 at both the desert and coastal field sites using HOBO data loggers (Onset Computer, Bourne, Mass., USA). For each shrub canopy the average temperature of four thermistors placed below, but not in contact with, four different leaves was recorded every $10 \mathrm{~min}$. To estimate how these canopy temperatures related to actual leaf temperatures, the thermistor measurements were compared to several leaf temperatures measured with 40-gauge type E thermocouples adhered to the underside of leaf surfaces with gas permeable tape. Thermocouple leaf temperatures were recorded with a Campbell data logger (Logan, Utah, USA).

\section{$T-F_{\mathrm{o}}$ measurement}

Stems with several healthy leaves were collected early in the morning and kept with their cut-end in water and acclimated to very low light $\left(<10 \mu \mathrm{mol} \mathrm{m} \mathrm{m}^{-2} \mathrm{~s}^{-1}\right)$ for $1-7 \mathrm{~h}$. Our measurements concur with previous reports that the duration of low light acclimation has no effect on the inflection temperature of the $T-F_{0}$ curve (data not presented; Logan and Monson 1999). Immediately prior to measurement a single entire leaf was collected and placed on damp filter paper on top of the ceramic surface of a $4 \times 4-\mathrm{cm}$ peltier thermoelectric heater (Melcor, Trenton, N.J., USA). A $4 \times 4-\mathrm{cm}$ Plexiglas cover with a compressible foam border was placed over the leaf and heater. The peltier heater was controlled by a LFI-3550 thermoelectric temperature controller (Wavelength Electronics, Bozeman, Mont., USA). Leaves were exposed to verylow-intensity far-red illumination (less than $1 \mu \mathrm{mol} \mathrm{m} \mathrm{m}^{-2} \mathrm{~s}^{-1}$ ) during measurements to maintain photosystem II in the oxidized state (Bilger et al. 1984; Valladares and Pearcy 1997). Steady-state fluorescence in the presence of far-red light was recorded every $5 \mathrm{~s}$ using a FMS2 fluorimeter (Hansatech, King's Lynn, Norfolk, England). Every $30 \mathrm{~s}$ the fluorimeter sent an analog voltage output to the LFI-3550 thermoelectric temperature controller, which altered the temperature set point to correspond to a linear increase of $1^{\circ} \mathrm{C}$ $\mathrm{min}^{-1}$. The temperature set point was monitored with a micro thermistor inside the chamber (Alpha Sensors, San Diego, Calif., USA). Leaf temperature was measured by two 40-gauge type E thermocouples (Omega, Stamford, Conn., USA) placed between the filter paper and the lower leaf surface. Thermocouple output was measured and recorded every $5 \mathrm{~s}$ using an HH509R thermocouple thermometer (Omega, Stanford, Conn., USA). Spatial temperature variation inside the chamber was checked using temperature-sensitive liquid crystal sheets with varying temperature ranges (Edmonds Scientific, Barrington, N.J., USA). We found that the temperature inside the chamber was uniform within approximately $0.5 \mathrm{~cm}$ from the edge of the chamber, and all fluorescence measurements were conducted inside that perimeter. The end of the fluorimeter fiber optic was placed over the Plexiglas chamber cover at a $60^{\circ}$ angle. The leaf was held at approximately $30^{\circ} \mathrm{C}$ for 1-2 min before the linear temperature increase was initiated.

Ten leaves of each species for both common environment and field populations were measured in this manner. Several parameters for each replicate were calculated and recorded as follows (Fig. 1A). The $50 \% F_{\mathrm{o}}$ rise temperature $\left(T_{50}\right)$ was recorded as the temperature at which $F_{\mathrm{o}}$ reached $50 \%$ of the variable range $\left[\left(F_{\mathrm{o}} \mathrm{max}-F_{\mathrm{o}} \mathrm{min}\right) / 2\right]$. The temperature at which $F_{\mathrm{o}}$ was at its maximum $\left(T_{\max }\right)$ was also tabulated. We calculated $T_{\text {crit }}$ as the intersection of two visually fit lines, one to the slow rise phase of the curve, and one to the fast rise phase. We also calculated the temperature at which the slope of the $T-F_{\mathrm{o}}$ curve reached $20 \%$ of its maximum $\left(T_{\mathrm{S} 20}\right)$. The instantaneous slope was calculated by linear interpolation across a $2^{\circ} \mathrm{C}$ range centered on the $F_{\mathrm{o}}$ measurement temperature.

\section{Statistical analysis}

Correlations among $T-F_{\mathrm{o}}$ parameters $\left(T_{\text {crit }}, T_{\mathrm{S} 20}, T_{50}\right.$, and $\left.T_{\max }\right)$ were calculated using Pearson's correlation coefficient. Correlations between July $y_{\max }$, AP and $\log _{10}$-transformed $T-F_{\mathrm{o}}$ parameters were calculated across the entire data set, and between PDI and $T-F_{\mathrm{o}}$ parameters for the chaparral species. Variation in $T-F_{\mathrm{o}}$ parameters between genera and environments was analyzed in a series of two-way ANOVAs. Differences between congeneric pairs in the common environment were analyzed with genus and native environment (desert vs coast) as fixed factors. Plasticity of $T-F_{0}$ parameters between the common environment and the field was tested for desert and coastal species separately with two-way ANOVAs with genus and growth environment as fixed terms. $T-F$ variation in the field was analyzed in two ways. For the congeneric pairs, a two-way ANOVA was used, with genus and field environment as fixed factors. In addition, overall differences in $T-F_{\mathrm{o}}$ parameters for all of the species at the desert and coastal field sites 
were analyzed by single-factor nested ANOVA with species nested in environment.

For the two-way ANOVAs, it can be argued that genus should be included as a random, rather than a fixed, factor. We assigned genus as a fixed factor for several reasons. First, the genera were chosen to facilitate paired comparisons between the desert and coastal species, and therefore do not constitute a random sample of species, as one might favor for an overall comparison of the desert and coastal flora (see Westoby et al. 1998). In addition, while the genera provide replicated evolutionary divergences between desert and coast, we do not consider them to be a random selection of equivalent sampling units (as in the case of replicate subjects in experimental research; see Sokal and Rohlf 1995). Each genus has a unique ecology and evolutionary history, which may lead to differences in the patterns of response. If genus is treated as a random term, it is impossible to conduct post hoc tests to evaluate the contributions of different genera to any significant interaction terms, yet these comparisons are of interests in the context of this study. Finally, with one exception (see result for species pairs in the field) the results were qualitatively similar when genera were treated as fixed or random, so for the reasons listed above we treated them as fixed. Statistical analysis was carried out using S-PLUS software (MathSoft, Cambridge, Mass., USA) and DataDesk (Data Description, Ithaca, N.Y., USA).

\section{Results}

Relationships among $T-F_{\mathrm{o}}$ parameters

All of the $T-F_{\mathrm{o}}$ parameters were significantly correlated (Fig. 2, Table 2). On average, $T_{\text {crit }}$ was $+0.21^{\circ} \mathrm{C}$ greater than $T_{\mathrm{S} 20} . T_{50}$ and $T_{\max }$ were +2.55 and $+6.35^{\circ} \mathrm{C}$ greater than $T_{\mathrm{S} 20}$ respectively. The measures $T_{\text {crit }}$ and $T_{\mathrm{S} 20}$ are very similar. Therefore $T_{\text {crit }}$ is excluded from subsequent analyses.

\section{Common environment}

There was a significant difference between genera and between coastal and desert species within genera for $T_{\mathrm{S} 20}$ (Table 3). Results are similar for $T_{50}$ and $T_{\max }$ (ANOVAs not reported). The genus $\times$ native environment interaction terms for $T_{\mathrm{S} 20}\left(F_{3,72}=12.60, P<0.001\right), T_{50}\left(F_{3,72}=16.26\right.$, $P=<0.001)$, and $T_{\max }\left(F_{3,72}=16.85, P<0.001\right)$ were all significant indicating that the magnitude of $T-F_{\mathrm{o}}$ differences between desert and coastal species were signifi-
Table 2 Pearson correlation coefficients for $T-F_{\mathrm{o}}$ parameters for all species and conditions ( $n=370, P \leq 0.01$ in all cases)

\begin{tabular}{lllll}
\hline & $T_{\mathrm{S} 20}$ & $T_{\text {crit }}$ & $T_{50}$ & $T_{\max }$ \\
\hline$T_{\max }$ & 0.845 & 0.876 & 0.935 & 1.00 \\
$T_{50}$ & 0.949 & 0.966 & 1.00 & \\
$T_{\text {crit }}$ & 0.972 & 1.00 & & \\
$T_{\mathrm{S} 20}$ & 1.00 & & & \\
\hline
\end{tabular}

Table 3 Two-way ANOVA tables for $T_{\mathrm{S} 20}$ for congeneric species in the common environment $(A)$, in the field $(B)$, and between the common environment and field for coastal $(C)$ and desert $(D)$ species. Genus, native environment (Nat. env.) and growth environment (Gr. env.) are modeled as fixed factors. $E$ Nested ANOVA for all species measured in the field. The last row of each section lists the error mean square $(M S)$

\begin{tabular}{|c|c|c|c|c|}
\hline & Factor & $d f$ & $F$ & $P$ \\
\hline A & $\begin{array}{l}\text { Genus } \\
\text { Nat. env. } \\
\text { Genus } \times \text { Nat. env. } \\
\text { Error }\end{array}$ & $\begin{array}{r}3 \\
1 \\
3 \\
72\end{array}$ & $\begin{array}{c}96.08 \\
20.33 \\
12.60 \\
\mathrm{MS}=0.93\end{array}$ & $\begin{array}{l}<0.001 \\
<0.001 \\
<0.001\end{array}$ \\
\hline B & $\begin{array}{l}\text { Genus } \\
\text { Nat. env. } \\
\text { Genus } \times \text { Nat. env. } \\
\text { Error }\end{array}$ & $\begin{array}{r}4 \\
1 \\
4 \\
110\end{array}$ & $\begin{array}{c}58.76 \\
56.31 \\
18.13 \\
\mathrm{MS}=1.54\end{array}$ & $\begin{array}{l}<0.001 \\
<0.001 \\
<0.001\end{array}$ \\
\hline $\mathrm{C}$ & $\begin{array}{l}\text { Genus } \\
\text { Gr. env. } \\
\text { Genus } \times \text { Gr. env. } \\
\text { Error }\end{array}$ & $\begin{array}{r}3 \\
1 \\
3 \\
72\end{array}$ & $\begin{array}{c}74.54 \\
66.36 \\
1.49 \\
\mathrm{MS}=1.49\end{array}$ & $\begin{array}{l}<0.001 \\
<0.001 \\
\mathrm{NS}\end{array}$ \\
\hline D & $\begin{array}{l}\text { Genus } \\
\text { Gr. env. } \\
\text { Genus } \times \text { Gr. env. } \\
\text { Error }\end{array}$ & $\begin{array}{r}3 \\
1 \\
3 \\
72\end{array}$ & $\begin{array}{c}123.78 \\
160.08 \\
16.49 \\
\mathrm{MS}=0.86\end{array}$ & $\begin{array}{l}<0.001 \\
<0.001 \\
<0.001\end{array}$ \\
\hline $\mathrm{E}$ & $\begin{array}{l}\text { Environment } \\
\text { Species nested in environment } \\
\text { Error }\end{array}$ & $\begin{array}{r}1 \\
14 \\
144\end{array}$ & $\begin{array}{l}167.40 \\
53.13 \\
\mathrm{MS}=4.00\end{array}$ & $\begin{array}{l}<0.001 \\
<0.001\end{array}$ \\
\hline
\end{tabular}

cantly different between genera. Ad hoc multiple comparisons indicated that coastal and desert Atriplex species were significantly different for $T_{\mathrm{S} 20}$ while the Eriogonum, Encelia and Salvia species pairs were not significantly different (Fig. 3). Each species mean $T_{\mathrm{S} 20}$, $T_{50}$ and $T_{\max }$ in the common environment is presented in Table 4.
Fig. 2 The relationship between $T_{\mathrm{S} 20}, T_{\text {crit }}, T_{50}$ and $T_{\text {max }}$ for the all common garden and field measurements of $T-F_{\mathrm{o}}$. Refer to Table 1 for definition of terms. For comparison, the diagonal one-to-one relationship is plotted
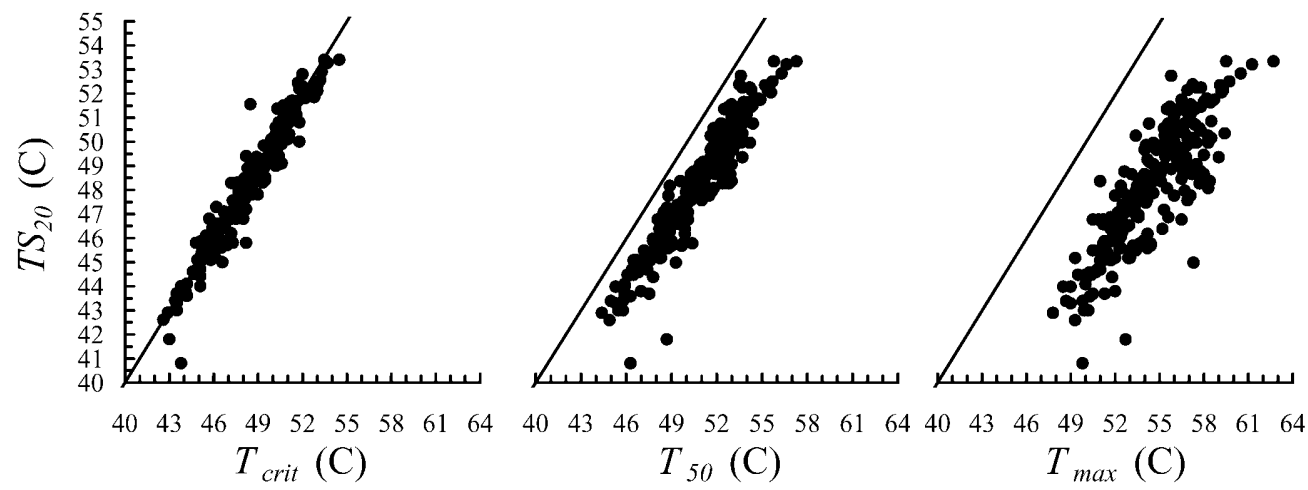
Fig. $3 T-F_{\mathrm{o}}$ curves for species pairs grown in the common environment. Each line is the average of ten replicates. For every genus, the black line represents the desert species and the gray line represents the coastal species. Species names are listed in Table 4

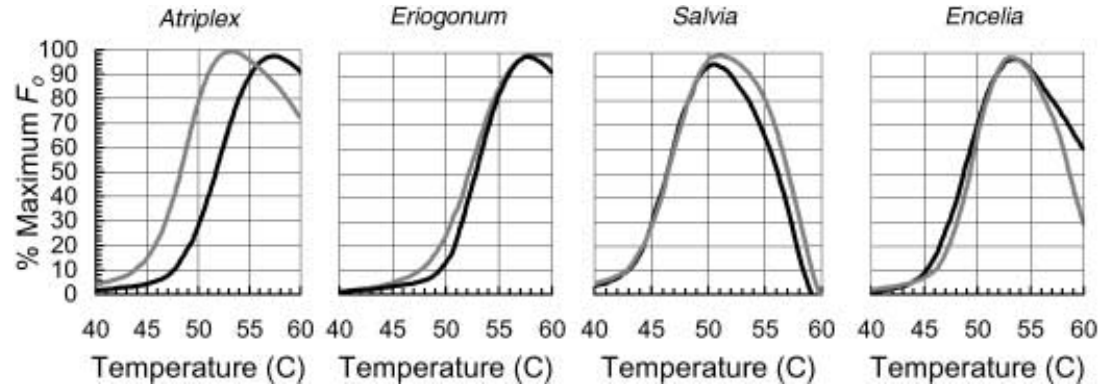

Table 4 Mean $T_{\mathrm{S} 20}, T_{50}$ and $T_{\max }$ for species in the common environment $(C E)$, and at the desert $(D)$, coastal $(C)$, and chaparral field sites. Values for $T_{\mathrm{S} 20}, T_{50}$ and $T_{\max }$ are the average of 10 replicates. Means that are significantly different between the CE and the field $(D$ or $C)$ are indicated with an asterisk. A GIS calculation of mean July maximum temperature ( $\left.J u l y_{\text {max }}\right)$ and average annual precipitation $(A P)$ inside each species' California range is also listed. The mean poteintial diurnal insolation $(P D I)$ inside the local distribution of species at the chaparral field site is also presented

\begin{tabular}{|c|c|c|c|c|c|c|c|c|c|c|c|c|}
\hline & \multirow{2}{*}{$\begin{array}{l}\text { July } \max \\
\left({ }^{\circ} \mathrm{C}\right)\end{array}$} & \multirow{2}{*}{$\begin{array}{l}A P \\
(\mathrm{~mm})\end{array}$} & \multirow[t]{2}{*}{$\mathrm{PDI}^{\mathrm{a}}$} & \multicolumn{3}{|c|}{$T_{\mathrm{S} 20}\left({ }^{\circ} \mathrm{C}\right)$} & \multicolumn{3}{|c|}{$T_{50}\left({ }^{\circ} \mathrm{C}\right)$} & \multicolumn{3}{|c|}{$T_{\max }\left({ }^{\circ} \mathrm{C}\right)$} \\
\hline & & & & $\mathrm{CE}$ & \multicolumn{2}{|l|}{ Field } & $\mathrm{CE}$ & \multicolumn{2}{|l|}{ Field } & $\mathrm{CE}$ & \multicolumn{2}{|l|}{ Field } \\
\hline \multicolumn{13}{|c|}{ Congeneric species in the common environment and at the desert and coastal field sites } \\
\hline $\begin{array}{l}\text { Atriplex hymenelytra }(\mathrm{D}) \\
\text { Atriplex leucophylla }(\mathrm{C}) \\
\text { Encelia farinosa }(\mathrm{D}) \\
\text { Encelia californica }(\mathrm{C}) \\
\text { Eriogonum fasiculatum }(\mathrm{D}) \\
\text { Eriogonum latifolium (C) } \\
\text { Isocoma acradenia (D) } \\
\text { Isocoma menziesii (C) } \\
\text { Salvia mohavensis (D) } \\
\text { Salvia leucophylla (C) } \\
\text { Salvia dorrii var. dorrii (D) } \\
\text { Salvia mellifera }(\mathrm{C})\end{array}$ & $\begin{array}{l}38.3 \\
25.2 \\
38.3 \\
28.9 \\
33.4 \\
22.8 \\
36.9 \\
30.7 \\
36.6 \\
29.7 \\
32.4 \\
29.7\end{array}$ & $\begin{array}{l}148.9 \\
545.8 \\
153.5 \\
404.4 \\
555.8 \\
780.6 \\
208.1 \\
471.0 \\
173.2 \\
434.2 \\
288.4 \\
466.6\end{array}$ & & $\begin{array}{l}48.2 \\
45.3 \\
46.3 \\
47.2 \\
50.2 \\
48.9\end{array}$ & $\begin{array}{l}47.3^{*} \\
50.1^{*} \\
51.4^{*} \\
47.6 \\
45.6^{*} \\
45.5\end{array}$ & $\begin{array}{c}52.6^{*} \\
49.8^{*} \\
50.8 \\
49.9 \\
46.6^{*} \\
48.5\end{array}$ & $\begin{array}{l}51.9 \\
48.3 \\
49.0 \\
49.4 \\
52.9 \\
52.2\end{array}$ & $\begin{array}{l}48.7 \\
52.0^{*} \\
53.1 \\
49.8 \\
48.3^{*} \\
47.4\end{array}$ & $\begin{array}{l}55.7 * \\
52.7 * \\
53.2 \\
53.2 \\
49.2 * \\
51.2\end{array}$ & $\begin{array}{l}56.9 \\
53.1 \\
52.9 \\
52.9 \\
57.2 \\
57.8\end{array}$ & $\begin{array}{l}53.3 \\
54.8^{*} \\
56.3 \\
52.9 \\
53.0^{*} \\
50.7\end{array}$ & $\begin{array}{l}59.7 * \\
55.8^{*} \\
57.5 \\
56.4 \\
52.7 * \\
54.9\end{array}$ \\
\hline Species at the chaparral field site & & & & $T_{\mathrm{S} 20}$ & & & $T_{50}\left({ }^{\circ}\right.$ & & & $T_{\max }$ & & \\
\hline $\begin{array}{l}\text { Adenostema fasiculatum } \\
\text { Artemisia californica } \\
\text { Baccharis pilularis } \\
\text { Ceanothus cuneatus } \\
\text { Ceanothus oliganthus } \\
\text { Cercocarpus betuloides } \\
\text { Dirca occidentalis } \\
\text { Eriodictyon californicum } \\
\text { Heteromeles arbutifolia } \\
\text { Lepechinia calycina } \\
\text { Lonicera hipidula } \\
\text { Lotus scoparius } \\
\text { Marah fabaceous } \\
\text { Mimulus aurantiacus } \\
\text { Prunus ilicifolia } \\
\text { Quercus agrifolia } \\
\text { Rhamnus californica } \\
\text { Rhamnus crocea } \\
\text { Ribes californicum } \\
\text { Sambucus mexicana } \\
\text { Toxicodendron diversilobum }\end{array}$ & $\begin{array}{l}30.8 \\
29.5 \\
30.4 \\
30.4 \\
30.6 \\
29.8 \\
28.4 \\
31.7 \\
32.1 \\
30.9 \\
30.6 \\
33.2 \\
31.85 \\
32.9 \\
30.1 \\
29.6 \\
30.1 \\
30.1 \\
30.5 \\
30.8 \\
31.7\end{array}$ & $\begin{array}{l}762.8 \\
463.9 \\
770.1 \\
863.3 \\
786.1 \\
857.5 \\
716.3 \\
778.4 \\
689.6 \\
890.4 \\
807.4 \\
660.7 \\
713.6 \\
642.6 \\
727.1 \\
683.6 \\
848.1 \\
848.8 \\
782.4 \\
703.5 \\
720.9\end{array}$ & $\begin{array}{l}15.7 \\
16.8 \\
13.6 \\
15.2 \\
14.1 \\
14.3 \\
11.6 \\
16.6 \\
13.8 \\
14.7 \\
14.0 \\
15.3 \\
11.9 \\
14.4 \\
12.2 \\
14.6 \\
10.8 \\
14.7 \\
12.9 \\
15.2 \\
10.9\end{array}$ & $\begin{array}{l}46.2 \\
45.2 \\
46.3 \\
43.2 \\
47.1 \\
47.0 \\
47.9 \\
45.0 \\
50.0 \\
45.1 \\
50.9 \\
44.2 \\
42.7 \\
44.5 \\
52.5 \\
50.6 \\
49.3 \\
48.7 \\
45.1 \\
46.8 \\
47.5\end{array}$ & & & $\begin{array}{l}51.9 \\
48.8 \\
48.0 \\
47.9 \\
51.0 \\
52.4 \\
51.5 \\
48.0 \\
51.5 \\
46.6 \\
54.4 \\
47.5 \\
46.5 \\
46.9 \\
55.3 \\
54.7 \\
53.8 \\
53.1 \\
49.0 \\
50.7 \\
52.3\end{array}$ & & & $\begin{array}{l}64.1 \\
53.9 \\
53.5 \\
57.8 \\
54.8 \\
57.1 \\
56.0 \\
52.3 \\
56.5 \\
52.7 \\
58.3 \\
53.2 \\
53.1 \\
50.2 \\
60.8 \\
62.4 \\
59.1 \\
58.6 \\
54.1 \\
55.6 \\
59.1\end{array}$ & & \\
\hline
\end{tabular}


A

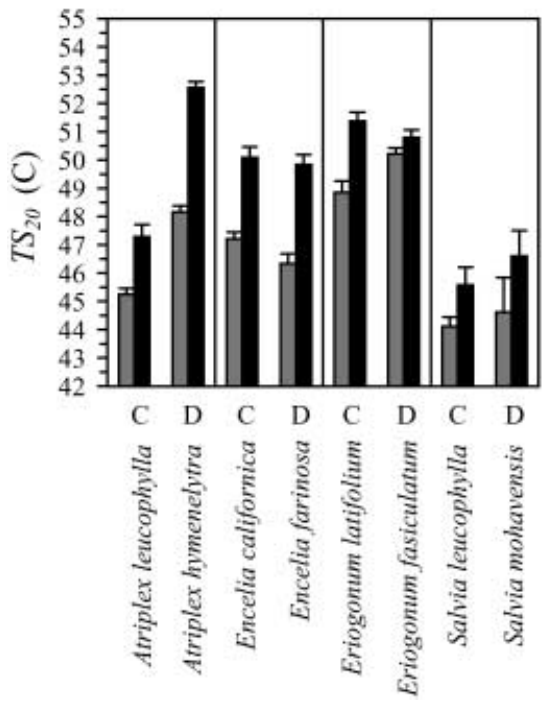

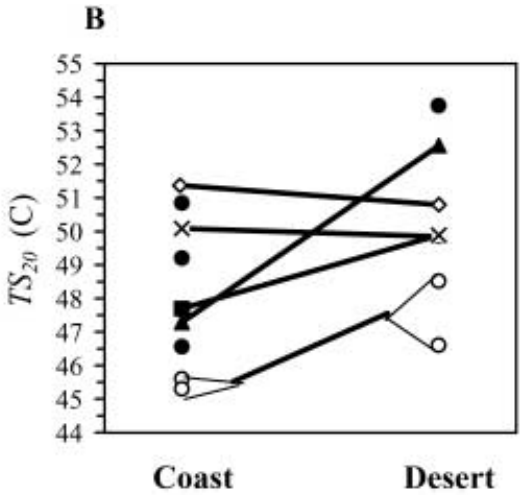

Fig. 4 A A comparison of desert $(D)$ and coastal $(C)$ congeneric species pairs for variation in $T_{\mathrm{S} 20}$ in the common environment (gray bars) and in the field (black bars). Error bars are the standard error of the mean. Measurements of $T_{\mathrm{S} 20}$ were greater in the field for all species. In the common garden, $T_{\mathrm{S} 20}$ for desert species of Atriplex and Eriogonum were greater compared to their coastal congeners. In the field the desert Atriplex and Salvia species had greater $T_{\mathrm{S} 20}$ while desert Encelia and Eriogonum species had slightly lower $T_{\mathrm{S} 20}$ compared to their coastal congeners. B is a comparison of all of the dominant shrub species at the desert and coastal field site. Congeneric Eriogonum (open diamond), Encelia (cross), Isocoma (black square), Atriplex (black triangle), and Salvia (open circle) species are connected by a solid line. The line for Salvia connects the mean for the two coastal and two desert species. Solid circles represent unpaired desert and coastal species. See Table 4 for a list of species

\section{Field}

If the field analysis is restricted to just the congeneric species pairs, there was a significant difference between genera and between coastal and desert congeners for $T_{\mathrm{S} 20}$ (Table 3, Fig. 4). The additional Salvia species were lumped together their coastal and desert congeners for this analysis. There was also a significant genusxenvironment interaction (Table 3). However, if genus is included as a random term, coastal and desert congeners are no longer significantly different $\left(F_{1,4}=3.11, P=0.15\right)$, but the difference between genera $\left(F_{4,110}=58.76, P<0.001\right)$ and the interaction between genera and environment $\left(F_{4,110}=27.84, P<0.001\right)$ is still significant. Ad hoc multiple comparisons for the model with genus as a fixed term (Table 3) indicated that the desert Atriplex, Isocoma, and Salvia all had significantly greater $T_{\mathrm{S} 20}$ than their coastal congeners while Eriogonum and Encelia species pairs were not significantly different (Table 4). Results are similar for $T_{50}$ and $T_{\max }$ (ANOVAs not reported).

When the analysis is expanded to include all of the species sampled in the field, ANOVAs with species nested in environment indicated that $T_{\mathrm{S} 20,} T_{50}$ and $T_{\max }$ were all significantly greater for desert species when com- pared to coastal species $\left(F_{1,14}=53.13\right.$ for $T_{\mathrm{S} 20}, 218.6$ for $T_{50}$, and 352.3 for $T_{\max }, P<0.001$ for all comparisons). On average, $T_{\mathrm{S} 20,} T_{50}$ and $T_{\max }$ were $2.0,3.8$, and $4.6^{\circ} \mathrm{C}$ greater in the desert. There were also significant differences between species within each community.

Plasticity between common environment and field measurements

Separate two-way ANOVAs for desert and coastal species between the common environment and the field indicated that $T_{\mathrm{S} 20}, T_{50}$ and $T_{\max }$ were all greater when measured in the field (Table 3, Fig. 4). There was a significant interaction between genus and growth environment for desert species, but not for coastal species. Coastal species had similar mean differences between the common environment and the field $\left(T_{\mathrm{S} 20}\right.$ was 2.0 , $2.9,2.5,1.5{ }^{\circ} \mathrm{C}$ greater in the field for coastal Atriplex, Encelia, Eriogonum, and Salvia species, respectively) while the difference for desert species varied considerably (Table 4). For example, the desert Atriplex species had a $4.4^{\circ} \mathrm{C}$ mean difference for $T_{\mathrm{S} 20}$ while the desert Eriogonum had only a $0.6^{\circ} \mathrm{C}$ difference. Results are similar for $T_{50}$ and $T_{\max }$ (ANOVAs not reported).

\section{Correlations with geographic niche parameters}

There was a significant negative correlation between AP and $\log \left(T_{\mathrm{S} 20}\right)$ for the field measurements $(R=-0.33$, $P=0.045, n=37)$, suggesting that species inhabiting areas with greater AP have lower $T-F_{\mathrm{o}}$ breakpoints. The correlation between AP and $\log \left(T_{50}\right)$ was not significant at a $5 \%$ confidence interval but there was a negative trend in the data $(R=-0.27, P=0.10, n=37)$. There were no significant relationships for July max $_{\text {ax }}$ or PDI. There was a significant negative correlation between July ${ }_{\max }$ and AP for the species in this study $(R=-0.60, P<0.01, n=37)$ and 
Fig. 5 Frequency distribution of shrub canopy temperatures at $\mathbf{A}$ the coastal and $\mathbf{B}$ desert field sites. Distributions represent the pooled 10-min average canopy temperatures for one individual of each species pair between May and July 2000
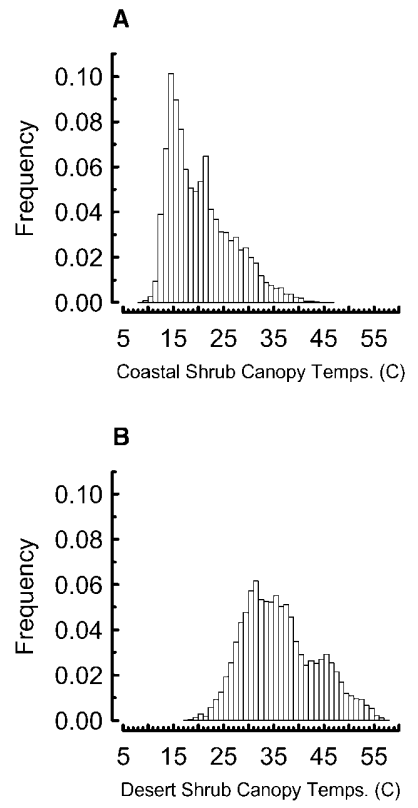

Table 5 Correlation coefficients for parameters of the temperature-dependent increase in fluorescence $\left(T_{S 20}, T_{50}\right.$, and $\left.T_{\max }\right)$ measured in the field and the July maximum temperature $\left(J u l y_{\max }\right)$ and annual precipitation $(A P)$ within the species' distribution. The correlation coefficients for potential diurnal insolation $(P D I)$ and fluorescence parameters for species at the chaparral field site are presented as well. $n=37$ for the July ${ }_{\max }$ and AP correlations, $n=21$ species for the PDI correlation

\begin{tabular}{lccc}
\hline & $T_{\mathrm{S} 20}$ & $T_{50}$ & $T_{\max }$ \\
\hline AP & $-0.33^{*}$ & -0.27 & -0.04 \\
July $_{\text {max }}$ & 0.15 & 0.27 & 0.23 \\
PDI & -0.32 & -0.32 & -0.18 \\
\hline
\end{tabular}

$* P \leq 0.05$

across all 7,929 taxa (including subspecies and varieties) in the California flora $(R=-0.57, P<0.01)$. Values for AP, $\mathrm{July}_{\max }, \mathrm{PDI}, T_{\mathrm{S} 20}, T_{50}$, and $T_{\max }$ are listed in Table 4, and the correlation coefficients are presented in Table 5.

\section{Leaf temperatures}

Shrub canopy temperatures (thermistor measurements) were within the range of leaf temperatures recorded by the thermocouples when measurements were taken simultaneously. Between May and July 2000 daytime shrub canopy temperatures were $18^{\circ} \mathrm{C}$ greater in the desert $\left(\right.$ mean $37^{\circ} \mathrm{C}$ ) than on the coast (mean $19^{\circ} \mathrm{C}$ ). Canopy temperatures in the desert frequently exceeded the $T_{\mathrm{S} 20}$ for all of the desert species (Fig. 5). During the same time period, shrub canopy temperatures at the coastal field site rarely, if ever, exceeded $T_{\mathrm{S} 20}$ for the coastal species.

\section{Discussion}

There are significant differences between species for photosynthetic thermotolerance measured by the temperature-dependent increase in steady-state fluorescence $\left(T-F_{0}\right)$. However, our data do not support the hypothesis that evolution of increased intrinsic photosynthetic thermotolerance is a general phenomenon for closely related species from desert and coastal environments. In the common garden, only the desert Atriplex species was significantly greater for all $T-F_{\mathrm{o}}$ parameters when compared to the coastal species. In the field, photosynthetic thermotolerance varied more between species within a community than between congeneric species across communities. However, in the field, desert species did have greater realized photosynthetic thermotolerance on average than coastal species.

Our study concurs with other studies indicating that plant species have a large capacity for plastic acclimation of photosynthetic thermotolerance (Seemann et al. 1979, 1986; Berry and Bjorkman 1980; Raison et al. 1982; Downton et al. 1984). Seven out of eight species were significantly different for $T_{\mathrm{S} 20}$ and five out of eight were significantly different for $T_{50}$ and $T_{\max }$ between common environment and field measurements. The magnitude of plasticity within a species was greater than the magnitude of evolved differences between the coastal and desert congeners. Others have reported even greater plasticity (Seemann et al. 1979, 1986; Raison et al. 1982; Downton et al. 1984). If we were able to acclimate plants to a number of different common environments or make measurements in the field on several occasions, we may have found an even greater range of photosynthetic thermal acclimation.

Photosynthetic thermotolerance was always lower for plants grown in the common environment. The mean temperature in the glass house was similar to the coastal environment, but the difference between the controlled environment and field measurements was only slightly smaller for coastal species compared to desert species. In the glass house the temperature regime was fairly constant $\left(25^{\circ} \mathrm{C}\right.$ day $/ 15^{\circ} \mathrm{C}$ night), water and nutrients were never limiting, and humidity levels were higher than in the field. Reflected radiation from the ground may significantly increase leaf temperature in the field, but in our common environment the glass house reflected part of this radiation. Therefore leaf temperatures may be reduced compared to the field, and cues for high temperature photosynthetic acclimation were probably absent in the common environment. Temperatures that induce photosynthetic acclimation may be much lower than temperatures that lead to increased fluorescence. Plants at the coastal field site rarely experienced temperatures that would lead to increased fluorescence; however, periodic extreme leaf temperatures (during periods of very low wind velocity and high irradiation for example) may induce high temperature photosynthetic acclimation without exceeding $T_{\mathrm{S} 20}$. In the desert, leaf temperatures that cause an increase in fluorescence may be frequent (Fig. 5). 
Plasticity of photosynthetic thermotolerance suggests that whole plant fitness may be positively impacted by photosynthetic acclimation. The desert species in this study may have to cope with contrasting temperature regimes of extreme cold in the early season and extreme heat late in the season. In addition, most of the precipitation falls during the relatively cool winter season in these desert and coastal environments. Therefore, the capacity for photosynthetic acclimation may be an adaptation for survival in variable environments (Seemann et al. 1979, 1986; Berry and Bjorkman 1980; Downton et al. 1984). A decline in net photosynthetic rates at all temperatures is sometimes associated with acclimation to high temperatures, yet this is not always the case (Seemann et al. 1979, 1986; Berry and Bjorkman 1980; Havaux and Tardy 1996). Because of the great deal of plasticity in photosynthetic thermotolerance, species from stressful environments may be better able to maintain high temperature acclimated plastic states. Quantifying the cost of maintaining high temperature acclimated photosynthesis at low temperatures, and low temperature acclimated photosynthesis at high temperatures is critical for understanding this adaptive plasticity hypothesis.

Prior to our study, the most extensive study of fluorescence rise characteristics in relation to the native habitat of species was that of Smillie and Nott (1979). They investigated $T_{\text {crit }}$ variation for 30 different species of alpine, temperate and tropical plants. Their data indicated that tropical plants typically had higher $T_{\text {crit }}$ than temperate plants and that temperate plants had higher $T_{\text {crit }}$ than alpine plants (the mean $T_{\text {crit }}$ for alpine, temperate and tropical plants was $39.8,44.1$, and $46.0^{\circ} \mathrm{C}$ respectively). However, except for the six alpine plants, which were collected from the field and grown in a common environment, the rest of the species were all agricultural species either bought at a local market or tested from nearby cultivated populations. Because of the potential plasticity of $T_{\text {crit }}$ dependent on growth environment reported by others (Seemann et al. 1979, 1986; Downton et al. 1984; Valladares and Pearcy 1997) and in the present study, it is not clear how well their data support the conclusion that plants from warmer climates have evolved greater intrinsic photosynthetic thermotolerance.

In the field we tested the hypothesis that species with warmer climate distributions have increased photosynthetic thermotolerance several ways. Discrete comparisons of desert versus coastal species at our two field sites indicated that on average, desert species did have higher $T_{\mathrm{S} 20}\left(+1.8^{\circ} \mathrm{C}\right), T_{50}\left(+3.3^{\circ} \mathrm{C}\right)$, and $T_{\max }\left(+4.3^{\circ} \mathrm{C}\right)$. As indicated above, these differences may be due to plastic acclimation of photosynthetic thermotolerance to local environmental conditions. Evolutionary differences between coastal and desert species, such as that indicated by the Atriplex species pair, may also contribute to this overall difference. We also found a significant negative correlation between $T_{\mathrm{S} 20}$ and average AP. However, there was no relationship between any of the $T-F_{\mathrm{o}}$ parameters with July $_{\max }$ (Table 5). The AP- $T_{\mathrm{S} 20}$ correlation is in the predicted direction; however it is difficult to explain why it is independent of any correlation between $T-F_{\mathrm{o}}$ and July $_{\max }$ because species ranges with high AP typically

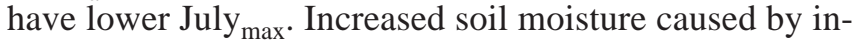
creased precipitation may affect plant water status and transpiration, which may modulate plant stress independent of average air temperature. Previous studies have shown that the osmotic state of a leaf affects the $T-F_{\mathrm{o}}$ relationship (Seemann et al. 1979, 1986; Valladares and Pearcy 1997). Therefore, water stress may be as important as temperature stress for interpreting the evolution of photosynthetic thermotolerance.

Acclimation of photosynthesis to local climate conditions may obscure correlations with any coarse scale climate parameter. Therefore, the microclimate distribution of species with respect to local topography and vegetation cover may be very important for interpreting variation in photosynthetic thermotolerance. We expected that species that inhabit warmer microclimates would have greater photosynthetic thermotolerance. In an effort to address this, we quantified the microclimate distribution of all the woody shrubs in a northern California chaparral and calculated a mean index of PDI from a GIS model (Ackerly et al., in press). In the early summer we measured the $T-F_{\mathrm{o}}$ response of 21 species in the chaparral community. Interestingly, there was no relationship between PDI and any of the $T-F_{\text {o }}$ parameters, despite the fact that mid-day leaf temperatures can vary by $12^{\circ} \mathrm{C}$ across these microclimate extremes (Knight, unpublished data). Because we measured $T-F_{\mathrm{o}}$ early in the summer, plants growing at sites with greater PDI may not have experienced environmental conditions that induce high temperature photosynthetic acclimation. If we had measured $T-F_{\mathrm{o}}$ later in the summer, perhaps we would have found a relationship. On the other hand, intrinsic photosynthetic thermotolerance may not be a factor that contributes to the microclimate distribution of species in the chaparral (Ackerly et al., in press).

The evolutionary trajectory with respect to environment (i.e. into the desert from the coast, or out of the desert to the coast) may be important for interpreting variation in photosynthetic thermotolerance between species. For example, if ancestral species of the coastal Salvia and Encelia species were from the desert, and the capacity for high temperature photosynthetic acclimation was a neutral character in cool environments (i.e. no selection for or against the maintenance of that character), closely related desert and coastal species might have similar photosynthetic thermotolerance in a common environment. However, it may be that the species pairs in our study were too closely related for substantial evolutionary change in photosynthetic thermotolerance. Species with a longer evolutionary history associated with their current environment (i.e. coastal species derived from coastal species compared to desert species derived from desert species) may have indicated a greater divergence in intrinsic photosynthetic thermotolerance. Historic climate variability during the evolution of land plants may have favored species with a large capacity for plastic acclimation of photosynthesis. Species with a greater ca- 
pacity for acclimation may be more likely to radiate into desert and coastal environments on short evolutionary time scales. Therefore, genera with closely related desert and coastal species might be less likely to have evolved differences in intrinsic photosynthetic thermotolerance. In addition, whole plant thermotolerance (i.e. survival) and photosynthetic thermotolerance may not be correlated because photosynthesis only occurs when environmental conditions are favorable. Favorable conditions may be frequent enough even in environments with frequent and extreme high temperature stress. Therefore, whole plant tolerance of the extreme conditions may be the result of some other adaptation, independent of photosynthetic tolerance.

The fluorescence rise parameters $T_{\text {crit }}, T_{\mathrm{S} 20}, T_{50}$, and $T_{\max }$ were highly correlated with each other across the entire data set (Fig. 2). Data presented by Havaux (1993) indicated that $T_{\max }$ was $6.7^{\circ} \mathrm{C}$ greater than $T_{\text {crit }}$ for several measurements of $T-F_{\mathrm{o}}$ before and after heat acclimation of potato leaves (inferred from data presented in Fig. 3 of Havaux 1993). Smillie and Nott (1979) report that $T_{\max }$ was $8.3,6.8$, and $7.8^{\circ} \mathrm{C}$ greater than $T_{\text {crit }}$ for alpine, temperate and tropical plants respectively. Across 35 species in our study, $T_{\max }$ was on average $+6.04^{\circ} \mathrm{C}$ greater than $T_{\text {crit }}$. While not all parameters were significantly different for comparisons in which one parameter was, the differences between parameters were of the same sign regardless of their significance. The correlation between parameters weakens with increasing temperature differences between parameters (Fig. 2, Table 2). For $T_{\mathrm{S} 20}$ there were more significant differences between congeneric species in the common environment, and between the common environment and the field (Table 4). Interestingly, $T_{\mathrm{S} 20}$ was the only parameter that was significantly correlated with any of the climate parameters but only for AP. Because $T_{\mathrm{S} 20}$ is reproducible, less subjective, and its calculation can be easily automated, we suggest that subsequent studies involving the $T-F_{\mathrm{o}}$ response use this parameter.

Our common garden study indicates that variation in intrinsic photosynthetic thermotolerance may not be a consistent physiological difference between relatively closely related species with contrasting climate distributions. With that in mind, two further questions should be addressed: 1. What, if any, are the physiological differences between these species? Historical biogeographic factors, genetic drift and chance play a significant role in the process of speciation. This can lead to morphological and biological species with contrasting climatic distributions that have not undergone significant physiological adaptation. Physiological plasticity may allow species survive in a wide range of environments. Therefore, desert and coastal species may not be significantly different for many physiological traits when measured in a common environment. 2. What is the cost of plastic acclimation of photosynthesis? Though closely related desert and coastal species might have quite similar photosynthetic thermotolerance in a common environment, the maintenance of plastic photosynthetic states that species achieve in the field may have significant implications for daily carbon gain, growth, or fecundity. The underlying physiological traits that allow desert plants to maintain high temperature acclimated photosynthesis and maintain adequate growth and reproduction in thermally stressful environments may be more informative for understanding the evolution of whole plant thermotolerance than variation in intrinsic photosynthetic thermotolerance.

Acknowledgements We thank Joe Berry, Max Taub, and Nathan Sanders for helpful comments that improved the manuscript, Gina Kang, Carina Uraiquat and Sarah Kelly for assistance with data collection and plant care, and Robert Fulton, Mike Williams, and Nona Chiariello for research support at the Desert Studies Center, Sedgwick Preserve, and Jasper Ridge Biological Preserve, respectively. This study was funded in part from a Tri-Agency (DOE, NSF, USDA) Training Grant in Plant Biology an NSF Dissertation Improvement Grant (CAK, IBN-9902295), a research grant from Jasper Ridge Biological Preserve (CAK) and a Terman Fellowship from Stanford University (DDA).

\section{References}

Ackerly DD (2000) Taxon sampling, correlated evolution and independent contrasts. Evolution 54:1480-1492

Ackerly DD, Knight CA, Weiss SB, Barton K, Starmer KP (in press) Leaf size, specific leaf area and microhabitat distribution of chaparral woody plants: contrasting patterns in species level and community level analyses. Oecologia DOI 10.1007/s004420100805

Austin MP, Nicholls AO, Margules CR (1990) Measurement of the realized qualitative niche: environmental niches of five Eucalyptus species. Ecol Monogr 60:161-177

Berry JA, Bjorkman O (1980) Photosynthetic response and adaptation to high temperature in plants. Annu Rev Plant Physiol 31:491-543

Bilger HW, Schreiber U, Lange OL (1984) Determination of leaf heat resistance: comparative investigation of chlorophyll fluorescence changes and tissue necrosis methods. Oecologia 63:256-262

Bukhov NG, Sabat SC, Mohanty P (1990) Analysis of chlorophyll a fluorescence changes in weak light in heat-treated Amaranthus chloroplasts. Photosynth Res 23:81-87

Daly C, Neilson RP, Phillips DL (1994) A statistical-topographic model for mapping climatological precipitation over mountainous terrain. J Appl Meteorol 33:140-158

Daly C, Taylor G, Gibson W (1997) The PRISM approach to mapping precipitation and temperature. 10th Conference on Applied Climatology, American Meteorological Society, Reno, Nev. pp 10-12

Downton WJS, Berry JA, Seemann JR (1984) Tolerance of photosynthesis to high temperature in desert plants. Plant Physiol 74:786-790

Franklin J (1998) Predicting the distribution of shrub species in southern California from climate and terrain-derived variables. J Veg Sci 9:733-748

Havaux M (1992) Stress tolerance of photosystem II in vivo: antagonistic effects of water, heat and photoinhibition stresses. Plant Physiol 100:424-432

Havaux M (1993) Rapid photosynthetic adaptation to heat stress triggered in potato leaves by moderately elevated temperatures. Plant Cell Environ 46:461-467

Havaux M, Strasser RJ (1992) Antagonistic effects of red and farred light on the stability of photosystem II in pea leaves exposed to heat. Photochem Photobiol 55:621-624

Havaux M, Tardy F (1996) Temperature dependent adjustment of photosystem II in vivo: possible involvement of xanthophylls cycle pigments. Planta 198:324-333 
Hickman JC (1993) The Jepson manual: higher plants of California. University of California Press, Berkeley, Calif.

Larcher W, Wagner J, Tammathaworn A (1990) Effects of superimposed temperature stress on in vivo chlorophyll fluorescence of Vigna unguiculata under saline stress. J Plant Physiol 136:92-102

Logan BA, Monson RK (1999) Thermotolerance of leaf discs from four isoprene-emitting species is not enhanced by exposure to exogenous isoprene. Plant Physiol 120:821-825

Raison JK, Roberts JKM, Berry JA (1982) Correlations between the thermal stability of chloroplast (thylakoid) membranes and the composition and fluidity of their polar lipids upon acclimation of the higher plant, Nerum oleander, to growth temperature. Biochem Biophys Acta 688:218-228

Schreiber U, Armond PA (1978) Heat-induced changes of chlorophyll fluorescence in isolated chloroplasts and related heatdamage at the pigment level. Biochem Biophys Acta 502: $138-151$

Schreiber U, Berry JA (1977) Heat-induced changes of chlorophyll fluorescence in intact leaves correlated with damage of the photosynthetic apparatus. Planta 136:529-538

Seemann JR, Downton WJS, Berry JA (1979) Field studies of acclimation to high temperature: Winter ephemerals in Death Valley. Carnegie Inst Wash Yearb 79:157-162

Seemann JR, Downton WJS, Berry JA (1986) Temperature and leaf osmotic potential as factors in the acclimation of photo- synthesis to high temperature in desert plants. Plant Physiol 80:926-930

Smillie RM, Nott R (1979) Heat injury of leaves of alpine, temperate and tropical plants. Aust J Plant Physiol 6:135-141

Sokal RR, Rohlf FJ (1995) Biometry. Freeman, New York

Valladares F, Pearcy RW (1997) Interactions between water stress, sun-shade acclimation, heat tolerance and photoinhibition in the sclerophyll Heteromeles arbutifolia. Plant Cell Environ $20: 25-36$

Weis E (1982) The influence of metal cations and $\mathrm{pH}$ on the heat sensitivity of photosynthetic oxygen evolution and chlorophyll fluorescence in spinach chloroplasts. Planta 154:41-47

Westman WE (1991) Measuring realized niche spaces: climatic response of chaparral and coastal sage scrub. Ecology 72:16781684

Westoby M, Cunningham SA, Fonseca CM, Overton JM, Wright IJ (1998) Phylogeny and variation in light capture area deployed per unit investment in leaves: designs for selecting study species with a view to generalizing. In: Lambers $\mathrm{H}$, Poorter H, Van Vuuren MMI (eds) Inherent variation in plant growth: physiological mechanisms and ecological consequences. Backhuys, Leiden, pp 539-566

Yamane Y, Shikanai T, Kashino Y, Koike H, Satoh K (2000) Reduction of $\mathrm{Q}_{\mathrm{A}}$ in the dark: another cause of fluorescence $F_{\mathrm{o}}$ increases by high temperatures in higher plants. Photosynth Res 63:23-34 